\title{
TREATABILITY STUDY FOR POLYETHYLENE MICROENCAPSULATION OF COMMERCIALLY GENERATED DSSI ASH MIXED WASTE
}

L.W. Milian, P.R. Lageraaen, J.W. Adams, and P.D. Kalb

June 1998

Environmental Sciences Department

Brookhaven National Laboratory

Brookhaven Science Associates

Upton, Long Island New York 11973

Under Contract No. DE-AC02-98CH10886 with the 


\title{
DISCLAIMER
}

This report was prepared as an account of work sponsored by an agency of the United States Government. Neither the United State Government nor any agency thereof, nor any of their employees, not any of their contractors, subcontractors, or their employees, makes any warranty, express or implied, or assumes any legal liability or responsibility for the accuracy, completeness, or usefulness of any information, apparatus, product, or process disclosed, or represents that its use would not infringe privately owned rights. Reference herein to any specific commercial product, process, or service by trade name, trademark, manufacturer, or otherwise, does not necessarily constitute or imply its endorsement, recommendation, or favoring by the United States Government or any agency, contractor, or subcontractor thereof. The vies and opinions of authors expressed herein do not necessarily state or reflect those of the United States Government or any agency, contractor or subcontractor thereof.

\author{
Printed in the United States of America \\ Available from \\ National Technical Information Service \\ U.S. Department of Commerce \\ 5285 Port Royal Road \\ Springfiled, VA 22161
}




\title{
TREATABILITY STUDY FOR POLYETHYLENE MICROENCAPSULATION OF COMMERCIALLY GENERATED DSSI ASH MIXED WASTE*
}

\author{
L.W. Milian, P.R. Lageraaen, J.W. Adams, and P.D. Kalb
}

June 1998

Work Conducted for:

Envirocare of Utah, Inc.

Salt Lake City, UT 83101

${ }^{*}$ This work was performed under the auspices of the U.S. Department of Energy. 


\section{TABLE OF CONTENTS}

1. INTRODUCTION $\ldots \ldots \ldots \ldots \ldots \ldots \ldots \ldots \ldots \ldots \ldots \ldots \ldots \ldots \ldots$

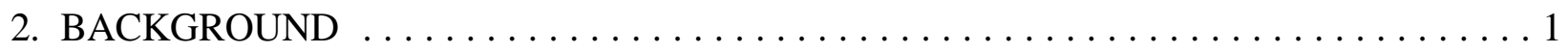

2.1 Kinetic Mixing Process and Equipment Description $\ldots \ldots \ldots \ldots \ldots \ldots \ldots \ldots$

2.2 Single-Screw Extrusion and Equipment Description $\ldots \ldots \ldots \ldots \ldots \ldots \ldots$

3. WASTE CHARACTERIZATION, PRE-TREATMENT AND STABILIZATION . . . . . 6

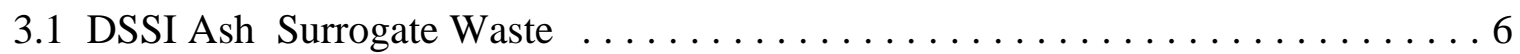

3.1.1 Polyethylene Microencapsulation of Treated Ash Surrogate Using the Kinetic Mixer . . . . . . . . . . . . . . . . . . . 7

3.1.2 Polyethylene Microencapsulation of Treated Ash Surrogate Using

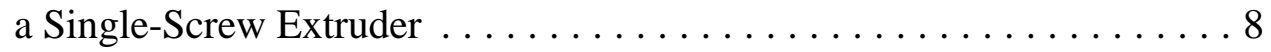

3.2 DSSI Ash Waste . . . . . . . . . . . . . . . . . . . . 10

3.2.1 Treated DSSI Ash Mixed Waste Characterization . . . . . . . . . . . 10

3.2.2 Polyethylene Microencapsulation of Treated DSSI Ash Mixed Waste Using a Killion Plastics Extruder . . . . . . . . . . . . . . 12

3.2.3 Polyethylene Microencapsulation of Treated DSSI Ash Mixed Waste using the Kinetic Mixer . . . . . . . . . . . . . . . 13

3.2.4 Polyethylene Microencapsulation of Untreated DSSI Ash Mixed Waste Using the Kinetic Mixer . . . . . . . . . . . . . 13

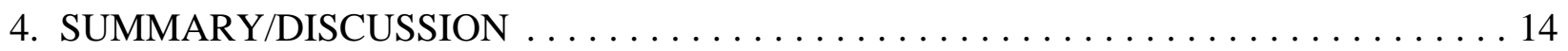

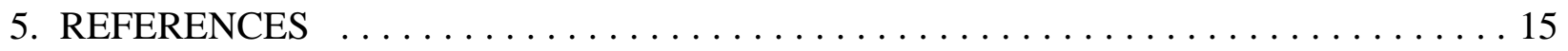




\section{LIST OF FIGURES}

Figure 1. Sketch of the pilot-scale kinetic mixer. $\quad \ldots \ldots \ldots \ldots \ldots \ldots \ldots \ldots$

Figure 2. Photograph of the LEX 100 pilot-scale kinetic mixer. . . . . . . . . . 4

Figure 3. Photograph of the Davis-Standard, single-screw plastics extruder. . . . . . . 5

Figure 4. Particle size distribution of treated ash surrogate. $\ldots \ldots \ldots \ldots \ldots \ldots$

Figure 5. A photograph of the polyethylene/surrogate discharging from the plastics extruder. . . . . . . . . . . . . . . . . . 9

Figure 6. TCLP pellets being molded as the molten polyethylene microencapsulated treated surrogate is discharging from the extruder die. . . . . . . . . . . 9

Figure 7. Teflon molded polyethylene/surrogate TCLP pellets $(<9.5 \mathrm{~mm}) \ldots \ldots \ldots$

\section{LIST OF TABLES}

Table 1. Stabilization Formula for Surrogate Ash Waste Preparation. . . . . . . . . . . 7

Table 2. Radionuclide Composition of the DSSI Ash Residue. . . . . . . . . . . 11

Table 3. Metal Composition of the DSSI Ash Residue. . . . . . . . . . . . . 12

Table 4. Summary of Selenium TCLP Leach Results Following

Polyethylene Microencapsulation. . . . . . . . . . . . . . . . . . 14 


\section{INTRODUCTION}

A limited scope treatability study for polyethylene microencapsulation of a Diversified Scientific Services, Inc. (DSSI) untreated and treated mixed waste ash was conducted at the Brookhaven National Laboratory (BNL) Environmental \& Waste Technology Center (EWTC) under sponsorship from Envirocare of Utah. Envirocare is a commercial radioactive and mixed waste treatment and disposal facility in Clive, UT that is licensed by the Nuclear Regulatory Commission and the Utah Divisions of Radiation Control and Solid and Hazardous Waste.

The untreated ash mixed waste was generated at Diversified Scientific Services, Inc., a commercially licensed hazardous, radioactive, and mixed waste treatment facility located in Oak Ridge, TN. This DSSI ash residue is the incineration by-product of hazardous organics and volume reduction of toxic and radioactive waste. Approximately thirty B-25 boxes of the ash residue were shipped to Envirocare of Utah and treated using their proprietary stabilization technology. Following stabilization, several batches of treated ash failed the Toxicity Characteristic Leach Procedure (TCLP)[1] for the Resources Conservation and Recovery Act (RCRA) metal, selenium, and consequently must now undergo additional treatment to meet the Environmental Protection Agency's (EPA) existing Universal Treatment Standards (UTS). Polyethylene microencapsulation using kinetic mixing and single-screw extrusion are two alternative processing technologies being considered by Envirocare to re-treat the DSSI ash waste. By microencapsulating, Envirocare expects to pass the EPA, Universal Treatment Standard limits for hazardous metals, specifically selenium.

A preliminary treatability study has been performed by BNL to determine the feasibility of microencapsulating a DSSI ash surrogate and a untreated, and treated DSSI ash residue in polyethylene. Process testing using kinetic mixing (patent pending) and BNL's single-screw extrusion process [2] was conducted to define appropriate operating conditions to facilitate the processing of this ash residue by Envirocare in the near future. Following successful processing, the molten products were molded to form cylindrical pellets, and sent to Mountain States Analytical, Inc. (Salt Lake City, Utah) for TCLP testing.

\section{BACKGROUND}

\subsection{Kinetic Mixing Process and Equipment Description}

BNL recently developed and demonstrated kinetic mixer processing for polyethylene microencapsulation under a Cooperative Research Development Agreement (CRADA) sponsored by U.S. DOE Office of Science and Technology and our industrial partner, EcoLEX, Inc. [3]

Kinetic mixing is a batch polymer processing technique that uses high shear and rapid rotational motion to create frictional heat sufficient to volatilize moisture and melt thermoplastics. Polymer and waste are fed to the mixer feed throat batch-wise, rapidly brought to melt temperature and mixed, then discharged as a thoroughly homogenized molten mass. The product may be suitable for final disposal or secondary treatment (e.g., extrusion or compression molding) may be necessary. As with extrusion processing, solidification of the product is assured on cooling. The robust agitation and mixing action potentially makes kinetic processors less sensitive to particle size limitations and 
permits a higher tolerance for moisture. Due to the design of the mixer, moisture can be vaporized throughout a batch cycle as frictional heat is used to overcome the latent heat of vaporization. Friction is generated as feed materials are sheared between the mixing blades and the mixing chamber wall and by particle to particle contact. Cycle time is dependent upon the feed composition, batch size and moisture content. Abrasive materials and increasing the batch size will decrease cycle time due to increased friction. Wastes containing a higher moisture content require additional cycle time since frictional heat will be used to vaporize the moisture. The operating temperature of the mixer is not pre-set so materials will melt and mix following sufficient kinetic energy generation. For example, substituting a thermoplastic with a higher melting point or lower melt flow will simply require a slightly longer cycle time.

Feasibility testing with waste surrogates and recycled plastics has been conducted by BNL using a pilot-scale kinetic mixer rated at $450 \mathrm{~kg} / \mathrm{hr}(1000 \mathrm{lb} / \mathrm{hr})$. The mixer was manufactured by LEX Technologies, Brampton, Ontario, Canada and was supplied by EcoLEX, Inc of Burlington, Ontario. The mixer consists of a $10 \mathrm{~L}$ batch mixing chamber, helical screw feed section, $7 \mathrm{~cm}$ rotating shaft with six mixing paddles, water cooled bearings, and pneumatically controlled inlet pinch gate and discharge door. The shaft, powered by a $150 \mathrm{HP}$ electric motor, rotates at a constant revolution resulting in a paddle tip speed of approximately $40 \mathrm{~m} / \mathrm{sec}$. Operation is controlled by a programmable logic controller, enabling the operator to coordinate feeding, charging, mixing and discharging of the materials. Charge and discharge functions can be automated based on motor load sensing (ammeter), a temperature probe signal, or pre-determined time intervals. Alternatively, these functions can be manually controlled by the operator.

The kinetic mixer used during this effort was not equipped with a temperature sensor so appropriate cycle times to successfully process each batch were determined based on the motor load or audible vibrations. At the completion of a cycle, the polymer "fluxes" by melting and mixing with the filler or waste materials. This point can usually be discerned because the molten polymer and waste now move as a single large mass within the mixing chamber resulting in an uneven load on the drive motor. The result is an increased load upon fluxing and vibrations in the mixer. Figures 1 and 2 show a sketch and a photograph of the LEX 100, a pilot-scale kinetic mixer used in this study. Both the untreated, and treated DSSI mixed waste ash residue, as well as the DSSI ash surrogate were mixed with polyethylene and processed in the kinetic mixer. 


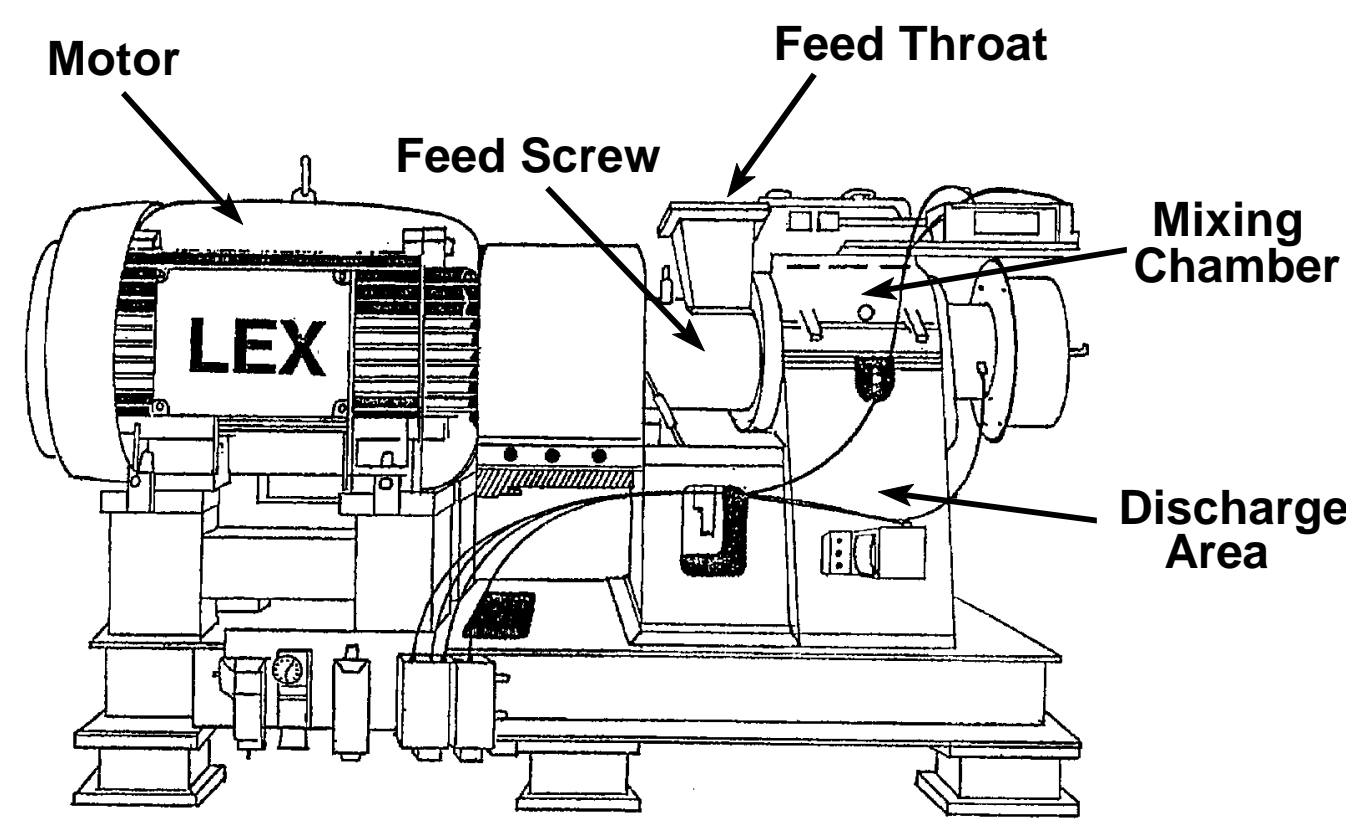

Figure 1. Sketch of the pilot-scale kinetic mixer.

\subsection{Single-Screw Extrusion and Equipment Description}

Polyethylene microencapsulation using a single-screw extruder results in an improved treatment alternative for low-level radioactive, hazardous and mixed wastes. This technology has been developed at BNL through feasibility testing, bench-scale development and full-scale demonstration. Process viability has been confirmed through bench-scale treatability studies with a broad range of actual and simulated mixed waste streams.[4,5,6,7,8,9,10] During processing, the waste materials are mechanically mixed into the molten polyethylene binder forming a homogeneous molten product with the waste evenly interspersed within a polyethylene matrix. Cooling of the product results in a solid monolithic waste form suitable for disposal. The process is not susceptible to chemical interactions between the waste and binder, enabling a wide range of acceptable waste types, high waste loadings, and technically simple processing under heterogeneous waste conditions.

The treated DSSI ash mixed waste was encapsulated in low-density polyethylene using a nonvented Killion extruder. Screw diameter of this bench-scale extruder is $32 \mathrm{~mm}$ (1.25 in) with an output capacity of approximately $16 \mathrm{~kg} / \mathrm{hr}(35 \mathrm{lb} / \mathrm{hr})$. Both waste and binder were fed separately through Accurate Model 301 volumetric feeders retrofitted with a Merrick loss-in-weight (LIW) control system. A computer controller for each feeder maintained real-time material delivery. A master controller regulated each feeder controller according to a programmed mixture ratio (waste loading), i.e., percentage of salt versus percentage of polyethylene. Accuracy of LIW feeders is quoted as $\pm 1.0 \%$ during steady-state operation. 


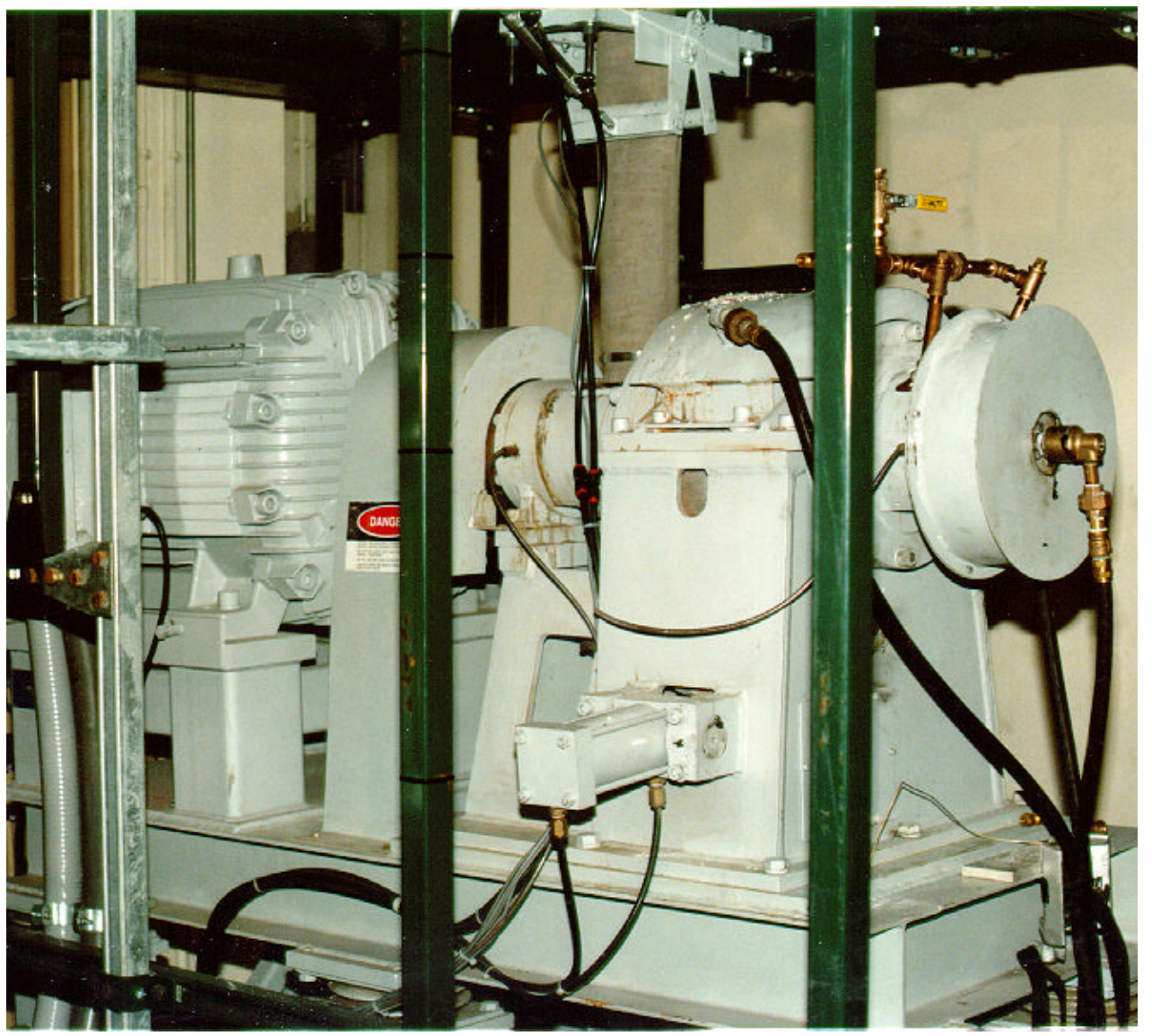

Figure 2. Photograph of the LEX 100 pilot-scale kinetic mixer.

Processing of the treated DSSI surrogate was performed using a $38 \mathrm{~mm}$ (1.5 in.) DavisStandard, vented, single-screw, plastics extruder. Both the surrogate and the polyethylene were metered accurately into the extruder at pre-set rates using two individual Series 300 Accu-Rate volumetric feeders. Accuracy of volumetric feeders is $\pm 2.0 \%$. Figure 3 is a photograph of the DavisStandard, single-screw plastics extruder.

Successful extrusion processing requires a dry waste since the temperature of the extruder exceeds the vaporization temperature for water. The moisture content generally cannot exceed $2 \%$ for vented extruders (Davis-Standard), or approximately $0.5 \%$ for non-vented extruders (Killion).

Also, the pilot scale kinetic mixer was determined to have a maximum particle size of $19 \mathrm{~mm}$, while the bench-scale extruder limit was approximately $2 \mathrm{~mm}$. Particle sizes were reduced to accommodate these requirements. However, larger scale equipment can successfully process larger particle sizes or broader particle size distributions. 


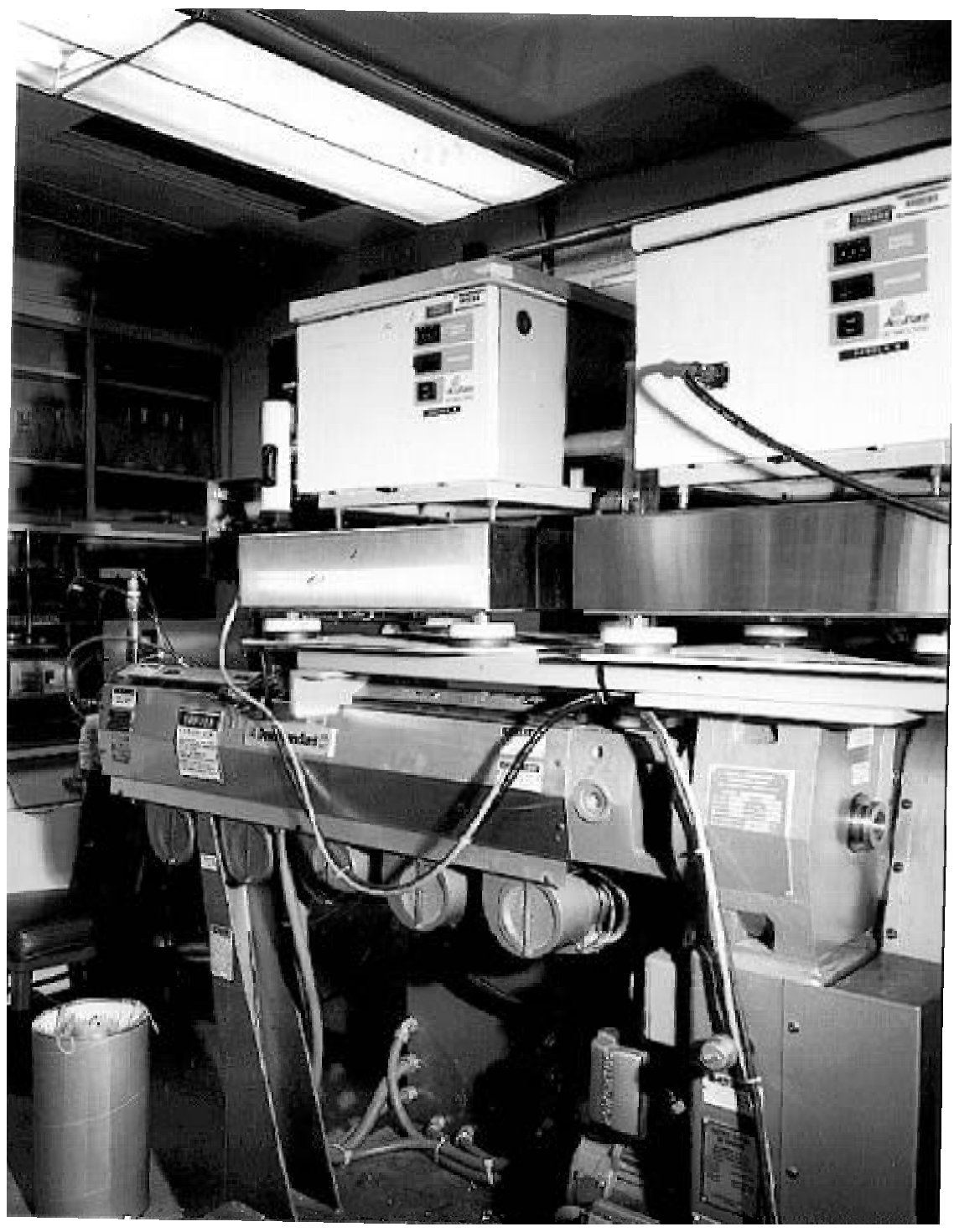

Figure 3. Photograph of the Davis-Standard, single-screw plastics extruder. 


\section{WASTE CHARACTERIZATION, PRE-TREATMENT AND STABILIZATION}

\subsection{DSSI Ash Surrogate Waste}

Before processing the actual DSSI mixed waste ash (untreated and treated), a nonradioactive ash surrogate was prepared and processed using both a bench scale, single-screw plastics extruder and a pilot-scale kinetic mixer. The "cold" processing using the kinetic mixer gave BNL an opportunity to develop operational parameters (e.g., flux cycle time, motor load/amperage during material fluxing), and to evaluate any potential problems (e.g., complete encapsulation of ash residue, moisture removal etc.) that may exist prior to microencapsulation of the contaminated untreated and treated DSSI ash waste stream. In addition, TCLP testing was conducted on the final waste product in accordance with the EPA protocol for the RCRA metal selenium. In all cases, the processed, molten waste product was formed into cylindrical TCLP test pellets $(<9.5 \mathrm{~mm})$, allowed to cool, removed from Teflon molds, and tested for selenium releases. The objective of this study was to pass TCLP testing for selenium (UTS limit: $0.16 \mathrm{mg} / \mathrm{L}$ ) following polyethylene microencapsulation of untreated and treated DSSI mixed waste ash.

An incinerator wood ash, with a moisture content of $14.6 \%$ (measurement performed on a Sartorius Moisture Analyzer at $110^{\circ} \mathrm{C}$ ), was used to simulate the DSSI ash residue. A selenium calibration standard was used to spike the surrogate ash waste at concentrations of $15 \mathrm{mg}$ selenium $/ \mathrm{Kg}$ of dry wood ash. The cement type used was Portland I and a small quantity of proprietary additive was used based on formula provided by Enviocare. The surrogate was prepared on a dried weight basis, with the adjustments for moisture content compensated for in the formulation. The stabilization formula for preparing the treated wood ash surrogate is shown in Table 1. A Hobart mixer was used to mix all the constituents of the surrogate to a homogeneous product. The surrogate components were added to the mixing container in the following order: wood ash, water, selenium, additive, then cement. Note, that after the addition of each component thorough mixing was employed. Also, to further ensure homogeneity, an additional 5-10 minutes of mixing was performed after all the surrogate ingredients were added to the mixing pot. The treated surrogate was then transferred to a five gallon metal pail for curing. A cover was placed over the pail and the mixture was cured for a minimum of 48 hours. This was sufficient time for the ash surrogate/cement mixture to solidify into a hard monolithic product.

Following the 48 hour curing period, the cement solidified surrogate was manually crushed into smaller sized particles. For kinetic mixing and single-screw extrusion all particle sizes were $<19$ $\mathrm{mm}$ and $<1.7 \mathrm{~mm}$, respectively. These particle size requirements ensured the effective microencapsulation of the ash waste stream using each of these processing methods. The moisture content of a representative portion of the solidified ash surrogate/cement product (particle size reduced to $<4.75 \mathrm{~mm}$ ) was measured using both oven-drying ( 2 hour drying period), and a Sartorius Moisture Analyzer at $110^{\circ} \mathrm{C}$. The average moisture content for the treated ash surrogate was 12.1 wt $\%$. 
Table 1. Stabilization Formula for Surrogate Ash Waste Preparation.

\begin{tabular}{|c|c|c|c|}
\hline \multirow{2}{*}{ Component } & \multirow{2}{*}{ Weight Ratio } & \multicolumn{2}{|c|}{ Batch Size } \\
\cline { 3 - 4 } & & Pounds & Kilograms \\
\hline Ash Surrogate & 1 & $25^{(1)}$ & $11.36^{(1)}$ \\
\hline Water & 0.15 & 3.75 & 1.7 \\
\hline Additive & 0.04 & 1.0 & 0.454 \\
\hline Cement $^{(2)}$ & 0.2 & 5.0 & 2.27 \\
\hline
\end{tabular}

(1) Value based on dry weight.

${ }^{(2)}$ Portland Type I.

\subsubsection{Polyethylene Microencapsulation of Treated Ash Surrogate Using the Kinetic Mixer}

Two formulations were considered in the polyethylene microencapsulation of ash surrogate using the kinetic mixer. Each processed batch size was calculated based on $2 \mathrm{Kg}$ totals. Surrogate/polyethylene formulas were calculated on a dry weight basis thereby compensating for surrogate moisture $(12.1 \mathrm{wt} \%$ ) removal during processing. The first mixture consisted of $46.8 \mathrm{wt} \%$ treated surrogate and $53.2 \mathrm{wt} \%$ low-density polyethylene (Melt Index $22 \mathrm{~g} / 10 \mathrm{~min}$ ). Prior to polyethylene microencapsulation, a particle size distribution of the surrogate was performed. The results are presented in Figure 4. Note, that the treated ash surrogate was randomly reduced in size, with $>85 \%$ of the particles measuring $>1.7 \mathrm{~mm}$. Kinetic mixing of the treated DSSI surrogate/PE resulted in a successful material flux after 46 seconds. However, there were no audible kinetic mixer vibrations and the motor load change (51 amp) was barely discernable. This made flux cycle time determination difficult. TCLP pellets were prepared from the molten product. After the pellets cooled and were removed from the Teflon mold, a TCLP test was performed (100g of pellets) to determine selenium releases. A Hewlett Packard, Model 4500 inductively coupled plasma/mass spectrophotometer (ICP/MS) was used to measure selenium concentrations in the leachates. Results revealed that the selenium concentration was below the detection limits of the instrument $(10 \mu \mathrm{g} / \mathrm{L})$, and therefore lower than the UTS limits for selenium $(0.16 \mathrm{mg} / \mathrm{L})$.

The second formulation included: $60 \mathrm{wt} \%$ treated DSSI surrogate, $37 \mathrm{wt} \%$ low-density polyethylene (Melt Index $22 \mathrm{~g} / 10 \mathrm{~min}$ ), and a $3 \mathrm{wt} \%$ sodium sulfide addition (quantity based on total surrogate weight). A particle size analysis of the treated ash surrogate was performed and is shown in Figure 4 . Nearly $84 \%$ of the particles were $>1.7 \mathrm{~mm}$. Kinetic mixing of surrogate/polyethylene resulted in an excellent product. The cycle time for the batch to flux was 52 seconds, and the motor load change was negligible (51 amps) during processing. The resultant molten product was used to mold TCLP pellets. Following mold removal, $100 \mathrm{~g}$ of pellets were tested in accordance with the TCLP. Once again the results were quite favorable. The selenium leach concentration for the polyethylene microencapsulation of a $60 \mathrm{wt} \%$ treated surrogate was below the ICP/MS detection limit $(10 \mu \mathrm{g} / \mathrm{L})$, and consequently below the EPA Universal Treatment Standard limit for selenium $(0.16 \mathrm{mg} / \mathrm{L})$. 


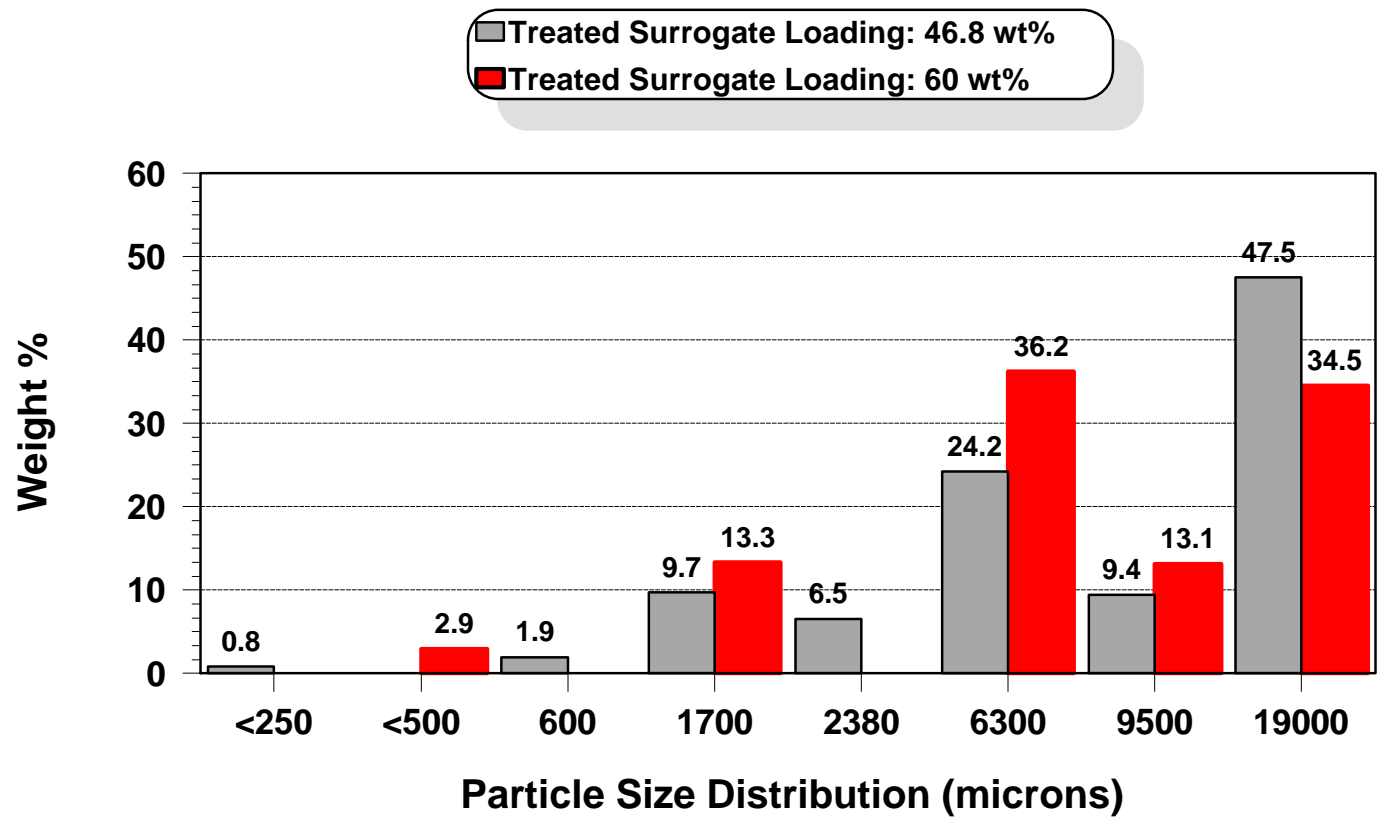

Figure 4. Particle size distribution of treated ash surrogate.

\subsubsection{Polyethylene Microencapsulation of Treated Ash Surrogate Using a Single-Screw Extruder}

Processing of the treated ash surrogate was also performed using a $38 \mathrm{~mm}$ (1.5 in.) DavisStandard, vented, single-screw, plastics extruder (Figure 3). Both the surrogate and the polyethylene were metered accurately into the extruder at pre-set rates using two individual Series 300 Accu-Rate volumetric feeders. Before processing, the waste stream required pulverizing to a particle size of $<1.7 \mathrm{~mm}$ and oven drying (overnight at $110^{\circ} \mathrm{C}$ ) to insure the effective microencapsulation of the treated ash surrogate in polyethylene. The processing formulation consisted of $60 \mathrm{wt} \%$ treated ash surrogate and $40 \mathrm{wt} \%$ low-density polyethylene (Melt Index $50 \mathrm{~g} / 10 \mathrm{~min}$ ). A photograph of the polyethylene/surrogate discharging from the extruder is shown in Figure 5. The material processed consistently and resulted in an excellent product. TCLP pellets were molded as the molten polyethylene microencapsulated treated surrogate was discharging from the extruder die (see Figure 6). Figure 7 shows Teflon molded polyethylene/surrogate TCLP pellets. After cooling and removal from the Teflon molds, 100g of pellets were TCLP tested for selenium releases. An ICP/MS was used to determine the selenium concentration in the leachates. Results show that polyethylene microencapsulation of the treated ash surrogate to be quite effective in reducing the release of selenium. The measured selenium concentration of the TCLP leachate was $19.6 \mu \mathrm{g} / \mathrm{L}$, and below the UTS limits of $0.16 \mathrm{mg} / \mathrm{L}$. 


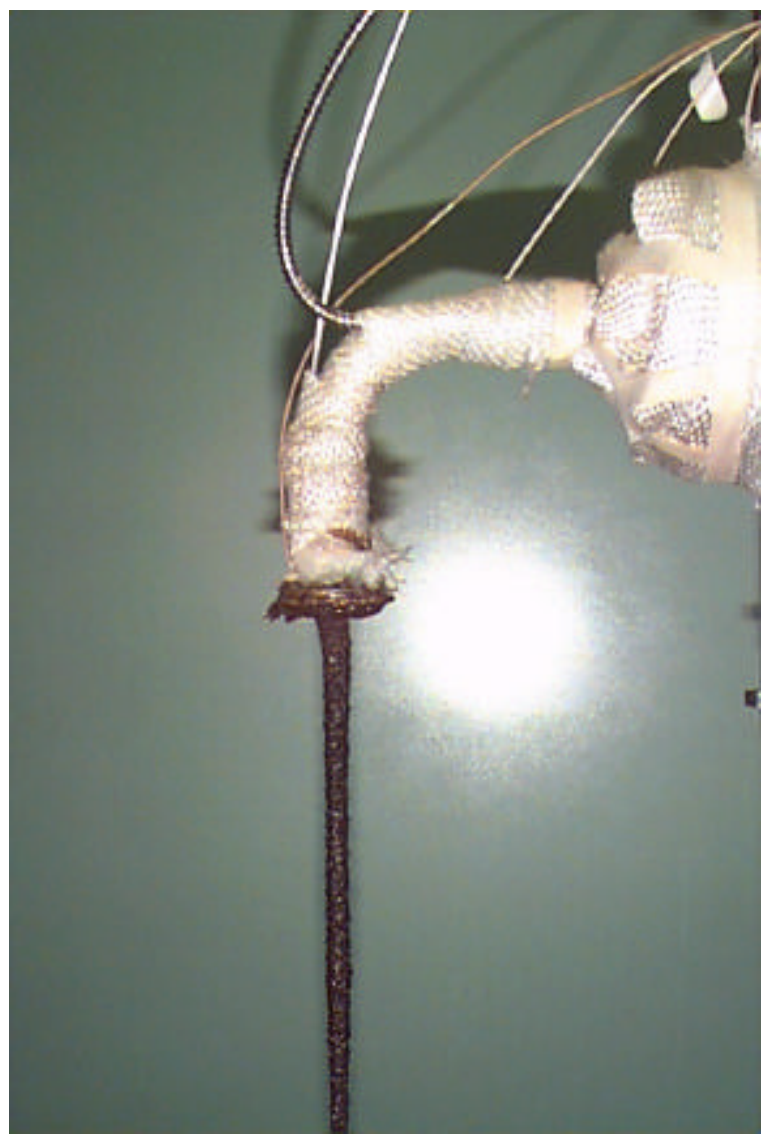

Figure 5. A photograph of the polyethylene/surrogate discharging from the plastics extruder.

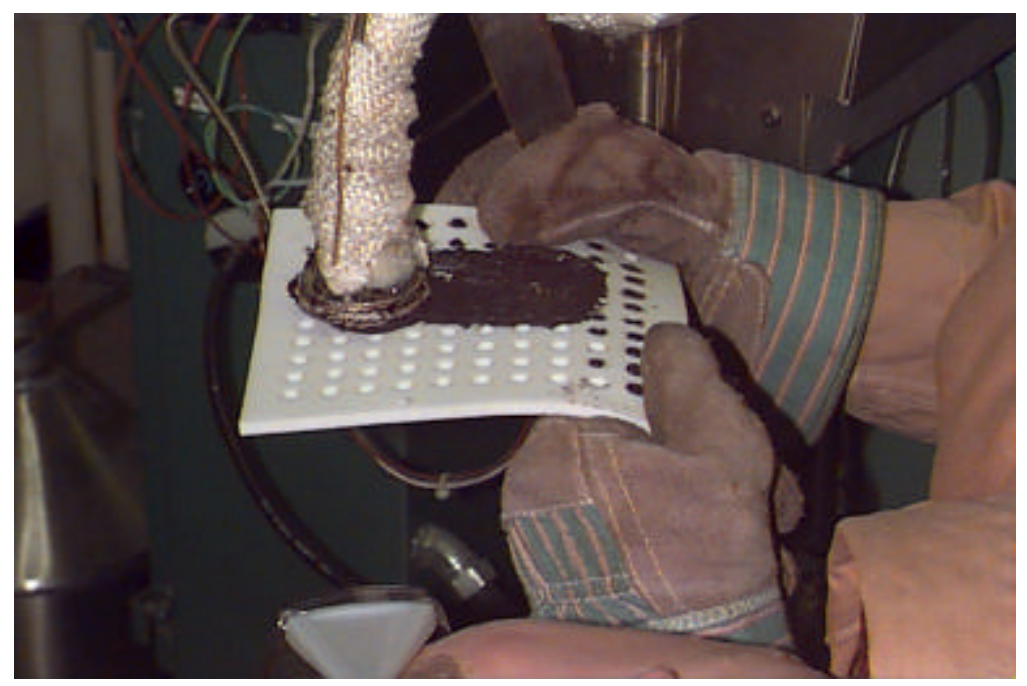

Figure 6. TCLP pellets being molded as the molten polyethylene microencapsulated treated surrogate is discharging from the extruder die. 


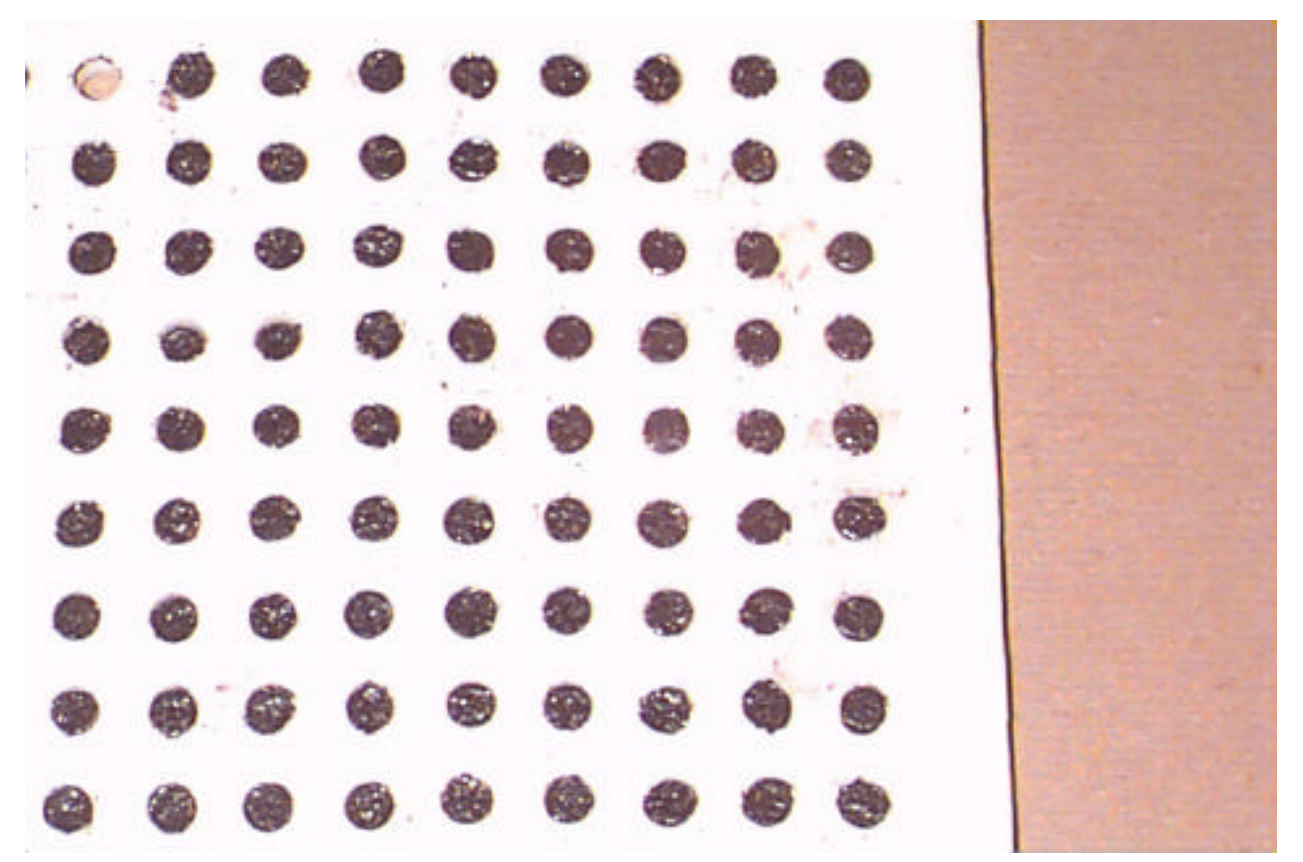

Figure 7. Teflon molded polyethylene/surrogate TCLP pellets $(<9.5 \mathrm{~mm})$

\subsection{DSSI Ash Waste}

\subsubsection{Treated DSSI Ash Mixed Waste Characterization}

A five gallon plastic pail containing cement treated DSSI ash residue was received from Envirocare of Utah. Tables 2 and 3 present a summary of the radionuclide and metals content of the DSSI ash residue. Three samples of treated DSSI ash residue were removed from the shipping pail, reduced to a particle size $<1.7 \mathrm{~mm}$, and a moisture content measurement was performed using a Sartorius Moisture Analyzer. This size reduction was performed initially to accommodate measurement using the moisture analyzer, however this particle size was also required for processing using single-screw extrusion. The average moisture content of the treated DSSI waste was 12.45 $\%$. All kinetic and extruder processing was performed using DSSI ash residue with a particle size reduced to $<19 \mathrm{~mm}$ and $<1.7 \mathrm{~mm}$, respectively. BNL has determined that these are the maximum particle sizes that can be effectively processed using these two technologies. 
Table 2. Radionuclide Composition of the DSSI Ash Residue.

\begin{tabular}{|c|c|c|c|}
\hline Radionuclide & $\begin{array}{c}\text { Concentration } \\
(\mathrm{pCi} / \mathrm{g})\end{array}$ & Radionuclide & $\begin{array}{c}\text { Concentration } \\
\text { (pCi/g) }\end{array}$ \\
\hline Ag-110m & 889 & I-129 & 39.8 \\
\hline Am-241 & 149 & K-40 & 2.62 \\
\hline Ba-133 & 0.906 & Mn-54 & 46.1 \\
\hline Be-7 & 2,820 & $\mathrm{Na}-22$ & 14 \\
\hline Bi-207 & 1.96 & Ni-59 & 13.2 \\
\hline C-14 & 252 & Ni-63 & 1,400 \\
\hline Ca-45 & 0.0849 & Pb-210 & 0.166 \\
\hline Cd-109 & 69.9 & Pu-238 & 0.221 \\
\hline Ce-141 & 3.2 & Pu-239 & 0.0901 \\
\hline Ce-144 & 244 & Pu-240 & 0.0867 \\
\hline Cm-242 & 0.0281 & Pu-241 & 9.21 \\
\hline $\mathrm{Cm}-243$ & 0.0356 & Pu-242 & 0.000065 \\
\hline Cm-244 & 0.0356 & Ra-226 & 6.88 \\
\hline Co-57 & 5.84 & Ru-106 & 1,130 \\
\hline Co-58 & 119 & S-35 & 171 \\
\hline Co-60 & 2,050 & Sb-124 & 1,100 \\
\hline Cr-51 & 23 & Sb-125 & 404 \\
\hline Cs-134 & 103 & Sr-89 & 0.539 \\
\hline Cs-137 & 76,300 & Sr-90 & 25,700 \\
\hline DU & 3,300 & Tc-99 & 1,790 \\
\hline Eu-152 & 0.597 & Th-230 & 0.648 \\
\hline Eu-154 & 24.4 & Th-232 & 85.2 \\
\hline Eu-155 & 380 & U-234 & 577 \\
\hline Fe-55 & 9,190 & U-235 & 481 \\
\hline De-59 & 0.0601 & U-236 & 0.244 \\
\hline Gd-153 & 356 & U-238 & 412 \\
\hline H-3 & 87.2 & U-Nat & 7,720 \\
\hline Hf-181 & 0.000498 & Zn-65 & 11.3 \\
\hline I-125 & 26,000 & Zr-95 & 0.945 \\
\hline
\end{tabular}


Table 3. Metal Composition of the DSSI Ash Residue.

\begin{tabular}{|c|c|}
\hline Metal & $\begin{array}{c}\text { Concentration } \\
(\mathbf{m g} / \mathbf{K g})\end{array}$ \\
\hline Antimony & $<10$ \\
\hline Arsenic & 5 \\
\hline Barium & 102 \\
\hline Beryllium & 0.2 \\
\hline Cadmium & 42.2 \\
\hline Chromium & 23.6 \\
\hline Lead & 40 \\
\hline Mercury & 0.5 \\
\hline Nickel & 14 \\
\hline Selenium & 15 \\
\hline Silver & 8.2 \\
\hline Thallium & 23 \\
\hline Vanadium & 3.7 \\
\hline Zinc & 220 \\
\hline
\end{tabular}

\subsubsection{Polyethylene Microencapsulation of Treated DSSI Ash Mixed Waste Using a Killion Plastics Extruder}

Following particle size reduction $(<1.7 \mathrm{~mm})$, the treated DSSI ash residue was transferred to glass Pyrex trays, and placed in an oven to dry $(18 \mathrm{hrs})$ at $110^{\circ} \mathrm{C}$ in order to meet moisture requirements for processing. A two kilogram batch size was used. The treated DSSI ash was processed using a $32 \mathrm{~mm}$ Killion extruder at the following ratios: $52.7 \mathrm{wt} \%$ treated DSSI ash waste/47.3 wt\% LDPE, and $60 \mathrm{wt} \%$ treated DSSI ash waste/40 wt\% LDPE. A low-density polyethylene with a melt index of $50 \mathrm{~g} / 10$ min was used. TCLP pellets were prepared in molds (cylindrical pellets measure $<9.5 \mathrm{~mm}$ ) as the molten mixture was being discharged from the extruder. After cooling and removal from the Teflon molds, $105 \mathrm{~g}$ of each formulation was shipped to Mountain States Analytical, Inc. (Salt Lake City, Utah) for TCLP selenium analysis (March 2, 1998). A high resolution ICP was used to measure the concentrations of selenium in the TCLP leachates. In both cases, the selenium concentrations were below the detection limit of the instrument $(15 \mu \mathrm{g} / \mathrm{L})$, and therefore below the TCLP UTS limit of $0.16 \mathrm{mg} / \mathrm{L}$, thus indicating the successful polyethylene microencapsulation of the treated DSSI ash waste. 


\subsubsection{Polyethylene Microencapsulation of Treated DSSI Ash Mixed Waste using the Kinetic Mixer}

All treated DSSI ash mixed waste was reduced in size to $<19 \mathrm{~mm}$ prior to processing in the kinetic mixer. A two kilogram batch size was used. The formulation used in the polyethylene microencapsulation of treated DSSI waste included $60 \mathrm{wt} \%$ treated DSSI ash waste, $37 \mathrm{wt} \%$ LDPE (Melt Index $22 \mathrm{~g} / 10 \mathrm{~min}$ ), and $3 \mathrm{wt} \%$ sodium sulfide. The quantity of treated ash waste to be encapsulated was based on a dry weight calculation because it was expected that the moisture would be removed (vaporized) during processing. The mixture was discharged after 65 seconds ( $52 \mathrm{amps}$ ) and the fluxed product was very soft indicating that the batch could have been removed earlier. Pellets were fabricated in Teflon molds and removed following cooling. A plastic container filled with $105 \mathrm{~g}$ of pellets was shipped to Mountain States Analytical, Inc. (Salt Lake City, Utah) for TCLP selenium analysis (March 2,1998). Results of this analysis show that the selenium concentrations in the TCLP leachate were below both the instrument (high resolution ICP) detection limit (15 $\mu \mathrm{g} / \mathrm{L}$ ) and UTS limits set for selenium $(0.16 \mathrm{mg} / \mathrm{L})$.

\subsubsection{Polyethylene Microencapsulation of Untreated DSSI Ash Mixed Waste Using the Kinetic Mixer}

A five gallon plastic pail, with individual zip-lock plastic bags (containing 1.5 - $2.0 \mathrm{Kg}$ per bag) of untreated DSSI ash residue was received from Envirocare of Utah. The moisture content (Sartorius Moisture Analyzer) of the untreated DSSI ash waste was $\sim 5.0 \mathrm{wt} \%$. The untreated DSSI ash residue was processed in the kinetic mixer at the following ratio: $50 \mathrm{wt} \%$ untreated DSSI ash residue, and $50 \mathrm{wt} \%$ LDPE (Melt Index $22 \mathrm{~g} / 10 \mathrm{~min}$ ). A $2 \mathrm{Kg}$ batch size was used for each process run. The amount of ash waste added was based on a dry weight calculation. The cycle time (51 sec) for this mixture was also difficult to discern due to the very small change in motor load (50 amps), and negligible audible vibration in the mixer. The product did flux successfully, but its soft consistency indicated slight overheating. The molten product was used to prepare $105 \mathrm{~g}$ of TCLP pellets. Following cool-down and removal from Teflon molds, the pellets were transferred to a plastic container and shipped to Mountain States Analytical, Inc. (Salt Lake City, Utah) for TCLP selenium analysis (March 2, 1998). TCLP leachate analysis showed polyethylene microencapsulation of the untreated DSSI waste to be successful because selenium concentrations were below the detection limit of the high resolution ICP $(15 \mu \mathrm{g} / \mathrm{L})$, and thus, below the TCLP UTS limits $(0.16$ $\mathrm{mg} / \mathrm{L})$.

A summary of TCLP selenium leach results following polyethylene microencapsulation are shown in Table 4. 
Table 4. Summary of Selenium TCLP Leach Results Following Polyethylene Microencapsulation.

\begin{tabular}{|c|c|c|c|c|c|}
\hline \multirow{2}{*}{ Waste Type } & \multicolumn{3}{|c|}{ Composition (wt \%) } & \multirow{2}{*}{$\begin{array}{l}\text { Processing } \\
\text { Method }\end{array}$} & \multirow{2}{*}{$\begin{array}{l}\text { TCLP Selenium } \\
\text { Concentration } \\
(\mathbf{m g} / \mathbf{L})^{(1)}\end{array}$} \\
\hline & Waste & Polyethylene & Additive & & \\
\hline \multirow{3}{*}{$\begin{array}{c}\text { Treated DSSI } \\
\text { Ash } \\
\text { Surrogate }\end{array}$} & 46.8 & 53.2 & na & $\begin{array}{l}\text { Kinetic } \\
\text { Mixing }\end{array}$ & $<0.010^{(2)}$ \\
\hline & 60 & 37 & 3 & $\begin{array}{l}\text { Kinetic } \\
\text { Mixing }\end{array}$ & $<0.010^{(2)}$ \\
\hline & 60 & 40 & na & Extrusion & 0.0196 \\
\hline \multirow{3}{*}{$\begin{array}{c}\text { Treated DSSI } \\
\text { Ash }\end{array}$} & 52.7 & 47.3 & na & Extrusion & $<0.015^{(2)}$ \\
\hline & 60 & 40 & na & Extrusion & $<0.015^{(2)}$ \\
\hline & 60 & 37 & 3 & $\begin{array}{l}\text { Kinetic } \\
\text { Mixing }\end{array}$ & $<0.015^{(2)}$ \\
\hline $\begin{array}{l}\text { Untreated } \\
\text { DSSI Ash }\end{array}$ & 50 & 50 & na & $\begin{array}{l}\text { Kinetic } \\
\text { Mixing }\end{array}$ & $<0.015^{(2)}$ \\
\hline
\end{tabular}

(1) Toxicity Characteristic Leach Procedure UTS limit for selenium is $0.16 \mathrm{mg} / \mathrm{L}$.

(2) Indicates instrument detection limits.

\section{SUMMARY/DISCUSSION}

Polyethylene microencapsulation of surrogate DSSI ash waste was successfully processed using both kinetic mixing and single-screw extrusion at the various waste loadings tested. Analysis of the surrogate TCLP extractant fluids for selenium releases resulted in values that easily passed UTS limits. Successful polyethylene microencapsulation was also demonstrated for processed untreated, and treated DSSI ash residue. Analytical results on TCLP leachates tested at Mountain States Analytical, Inc. show that selenium releases from polyethylene microencapsulated untreated, and treated DSSI ash residue were below UTS limits regardless of processing method. No polyethylene microencapsulation of untreated DSSI ash waste by extrusion was performed in this limited scope study. In addition, located in the Appendix of this report are the results of other leachate metals analyses performed on the polyethylene microencapsulated untreated, and treated ash TCLP pellets sent to Mountain States Analytical, Inc. Although BNL was primarily concerned with passing the TCLP UTS limits for selenium releases, other metals were simultaneously analyzed. All the results from these additional measurements were within UTS limits. 


\section{REFERENCES}

1. U.S. EPA, "Toxicity Characteristic Leaching Procedure (TCLP)," 40 CFR 261, Appendix II, U.S. Environmental Protection Agency, Washington, D.C., September 19, 1994.

2. Kalb,P.D., and P. Colombo, "Composition and Process for the Encapsulation and Stabilization of Radioactive, Hazardous, and Mixed Wastes," U.S. Patent Nos. 5,649,323, July 15, 1997, and 5,732364, March 24, 1998.

3. Lageraaen, P.R., J.W. Adams, L.W. Milian, and P.D. Kalb, "Thermoplastic Encapsulation Treatability Study of Fernald Silo 1 and Silo 3 Wastes," BNL Report in press.

4. Kalb, P.D., and P.R. Lageraaen, "Polyethylene Encapsulation Full-Scale Technology Demonstration," BNL-52478, Brookhaven National Laboratory, Upton, N.Y., 1995.

5. Kalb, P.D., and P.R. Lageraaen, "Full-Scale Technology Demonstration of a Polyethylene Encapsulation Process for Radioactive, Hazardous, and Mixed Wastes," Journal of Environmental Science and Health, Vol. A31, No. 7, pp. 1767-1780, 1996.

6. Kalb, P.D., J.H. Heiser, and P. Colombo, "Long-Term Durability of Polyethylene for Encapsulation of Low-Level Radioactive Hazardous, and Mixed Wastes," Emerging Technologies in Hazardous Waste Management III, D.W. Tedder and R.G. Pohland, eds., American Chemical Society Symposium Series 518, Washington, D.C., 1993.

7. Lageraaen, P.R., J.W. Adams, and P.D. Kalb, "Treatability Study for Polyethylene Microencapsulation of Commercially Generated Sodium Nitrate Salt Waste," Letter Report, Prepared for Envirocare of Utah, Inc. By Brookhaven National Laboratory, May 1997.

8. Lageraaen, P.R., and P.D. Kalb, Brookhaven National Laboratory, D.L. Grimmett, R.L. Gay and C.D. Newman, Rockwell International Corp., "Polyethylene Encapsulation of Molten Salt Oxidation Mixed Low-Level Radioactive Salt Residues," Third Biennial Mixed Waste Symposium, Baltimore, MD, August, 1995. BNL-62204.

9. Kalb, P.D., J.W. Adams, M. Meyer, and H. Holmes Burns, "Thermoplastic Encapsulation Treatability Study for a Mixed Waste Incinerator Off-Gas Scrubbing Solution,” Stabilization and Solidification of Hazardous, Radioactive and Mixed Wastes, 3rd Vol., ASTM STP-1240, American Society for Testing and Materials, W. Conshoohocken, PA, 1996.

10. Lageraaen, P.R., B.R. Patel, P.D. Kalb, and J. Adams, "Treatability Studies for Polyethylene Encapsulation of INEL Low-Level Mixed Wastes," BNL-62620, Brookhaven National Laboratory, Upton, N.Y., October 1995. 
